ORIGINAL ARTICLE

\title{
Unilateral flail chest is seldom a lethal injury
}

\author{
J B Borman, L Aharonson-Daniel, B Savitsky, K Peleg, the Israeli Trauma Group
}

Emerg Med J 2006;23:903-905. doi: 10.1136/emj.2006.037945

Background: The chest cage is a common target for traumatic damage. Although relatively rare, it is considered to be a serious condition with significant reported mortalities. As most flail injuries are accompanied by severe extrathoracic injuries, it is often difficult to pinpoint a single injury responsible for the patient's death.

See end of article for authors' affiliations

Aim: To investigate the factors related to mortality when flail injury is diagnosed.

Methods: Data from the Israel National Trauma Registry between 1998 and 2003 included 11966 chest

Correspondence to: Dr L Aharonson-Daniel, injuries (262 flail chest injuries) out of a total of 118211 trauma hospitalisations. Mortality figures were analysed to determine which factors, singly or in combination, influenced flail chest mortality.

Deputy Director, Israel

National Center for

Trauma and Emergency

Medicine Research,

Gertner Institute for

Epidemiology and Health

Policy Research, Sheba

Medical Center, Tel

Hashomer 52621, Israel

limorad@gertner.health.

gov.il

Accepted

9 September 2006

Results: Road crashes accounted for most flail injuries (76\%). The total mortality was $54(20.6 \%)$ of 262 patients with flail chest injuries. $13(20.4 \%)$ of the deaths occurred soon after admission to the emergency room and $37(68.5 \%)$ within the first $24 \mathrm{~h}$. Mortality in moderate to severe injuries (injury severity score (ISS) 9-24) was 3.6\% and that in critical injuries $28.5 \%$ (ISS >24). Mortality increased with age: $17 \%$ in those aged $<45$ years, $22.1 \%$ in those between 45 and 64 years and $28.8 \%$ in those $>65$ years. Age remained a risk for inpatient death when adjusted for severity. Mortality in isolated unilateral flail injury was not more than $6 \%$. Total mortality for traumatic brain injury (TBI) and flail was $34 \%$. Flail, TBI and other major injuries increased the mortality to $61.1 \%$.

Conclusions: Advanced age is associated with higher mortality. Isolated unilateral bony cage instability infrequently leads to death in patients who make it to the emergency department but rather its combination with additional extrathoracic trauma.

$\mathrm{F}$ lail chest is widely considered to be a serious injury with reported death rates ranging from $5 \%$ to $36 \%{ }^{1-5}$ By definition, flail occurs when the integrity of the thoracic rigid cage is compromised and a segment, its size depending on the number of fractured ribs or costal cartilages, loses its continuity with the rest of the thoracic cage and moves paradoxically during spontaneous respiration. The damage results from a blunt, high-impact blow of great force. In the elderly, with weakened skeletal tissue, lesser force may result in flail, and in the young, whose ribs are more flexible, greater force is invariably necessary. ${ }^{6}$ Concomitant underlying lung contusion may be expected. Moreover, the fractured ribs may lacerate the lung parenchyma, resulting in haemo/pneumothorax of varying severity.

\section{METHODS}

This is a retrospective study of patients recorded in the Israeli National Trauma Registry during the period between 1 January 1998 and 31 December 2003.

Until 2000, the database was fed by eight hospitals (six level 1 trauma centres in Israel and 2 regional centres). One regional trauma centre was added in 2001 and another in 2003, totalling 10 hospitals.

Data recorded include patient's demographic details, information on the injury (diagnosis and circumstances), hospital resource utilisation, length of stay and disposition. SAS statistical software was used for data analysis. Statistical analysis included conventional tests such as $\chi^{2}$ tests for categorical data, t tests for continuous variables and logistic regression, which was performed to investigate models with multiple variables. A value of $\mathrm{p}<0.05$ was considered to be significant.

Mortality figures were analysed to determine which of the following factors, singly or in combination, influenced flail chest mortality: mechanism of injury, time of death, severity of injury, age and sex, traumatic brain injury (TBI) and other associated injuries-whether intrathoracic or extrathoracic, and whether the flail was unilateral or bilateral.

\section{RESULTS}

Patients

The national trauma registry lists a total of 118211 entries in the relevant period, 11966 of which are chest injuries. The frequency of chest injuries has remained steady at about 2000/year. A total of 262 cases diagnosed with flail chest and alive at the time of arrival to the emergency room constitute the cohort for this investigation.

Injury mechanism and severity

Road crashes account for $76 \%$ of injuries, whereas falls account for $14 \%$. ISS was listed as moderate (9-14) in $0.8 \%$, severe $(16-24)$ in $30.9 \%$ and critical $(>25)$ in $68.3 \%$ of the patients (table 1 ).

\section{Location of damage}

In only 28 patients $(11 \%)$ was the injury confined to the thorax, of whom $6(2.3 \%)$ had isolated thoracic cage injury with no serious damage to intrathoracic structures. The remaining 234 patients had additional extrathoracic injuries. Seventy $(26.7 \%)$ of these flails were accompanied by severe TBI. Bilateral flail was diagnosed in 34 (13\%), and haemo/ pnemothorax in $34(13 \%)$. Liver laceration occurred in 22 $(8.4 \%)$ and myocardial injury in $11(4.2 \%)$ patients. Limb injuries $(\mathrm{n}=183,69.9 \%)$, often multiple, commonly accompanied trunk and head injuries.

\section{Outcome}

The total number of inpatient deaths was 54 (20.6\%) of the total of 262 patients who arrived alive at the emergency

Abbreviations: AIS, abbreviated injury score; ISS, injury severity score; $\mathrm{TBI}$, traumatic brain injury 


\begin{tabular}{|c|c|c|}
\hline & $\%$ & n \\
\hline \multicolumn{3}{|l|}{ Sex } \\
\hline Male & 77.9 & 204 \\
\hline Female & 22.1 & 58 \\
\hline \multicolumn{3}{|l|}{ Age (years) } \\
\hline $0-14$ & 1.9 & 5 \\
\hline $15-24$ & 9.2 & 24 \\
\hline $25-44$ & 33.6 & 88 \\
\hline $45-64$ & 30.5 & 80 \\
\hline$>65$ & 24.0 & 63 \\
\hline Unknown & 0.8 & 2 \\
\hline \multicolumn{3}{|l|}{ Mechanism } \\
\hline Transport & 76.0 & 199 \\
\hline Drivers & 32.8 & 86 \\
\hline Pedestrians & 20.6 & 54 \\
\hline Other & 22.6 & 59 \\
\hline Falls & 13.7 & 36 \\
\hline Intentional & 4.2 & 11 \\
\hline Other & 6.1 & 16 \\
\hline \multicolumn{3}{|l|}{ Severity } \\
\hline ISS 1-8 & 0.0 & 0 \\
\hline ISS 9-14 & 0.8 & 2 \\
\hline ISS $16-24$ & 30.9 & 81 \\
\hline ISS $>24$ & 68.3 & 179 \\
\hline \multicolumn{3}{|c|}{$\begin{array}{l}\text { Hospital stay (of survivors, days; } \\
n=208 \text { ) }\end{array}$} \\
\hline$<2$ & 6.3 & 13 \\
\hline $3-7$ & 12.0 & 25 \\
\hline $8-14$ & 22.1 & 46 \\
\hline$>15$ & 55.8 & 116 \\
\hline Unknown & 3.8 & 8 \\
\hline Died & 20.6 & 54 \\
\hline
\end{tabular}

department. Of these, 13 (24\%) succumbed in the emergency department, $37(68.5 \%)$ died within $24 \mathrm{~h}$ and 40 (74\%) within $48 \mathrm{~h}$. Of the 54 fatalities, $46(85.2 \%)$ had died within 1 week and $53(98 \%)$ within 4 weeks; 1 patient died after 68 days (70-year-old man, a pedestrian with multiple injuries). Bilateral flail increased the total mortality to $50 \%$ (17 of 34).

Mortality rose with age, and with severity (table 2). When controlling for severity, elderly patients (aged $\geqslant 65$ ) still had a significantly higher chance $(\mathrm{p}<0.02)$ of dying compared with young patients (double than patients aged $<45$ ).

The inpatient death rate among all injured in road crashes was $19.6 \%(n=39)$, ranging from $29.6 \%(n=16)$ among pedestrians, to $17.2 \%(\mathrm{n}=5)$ among car passengers and to $12.8 \%(\mathrm{n}=11)$ among car drivers. A mortality of $19.4 \%$ $(\mathrm{n}=7)$ was recorded among those injured due to fall and $29.6 \%(n=8)$ among those injured due to other reasons. There was no significant correlation between injury mechanism and inpatient death rate, when adjusted for injury

Table 2 Inpatient mortality rates by age and severity groupings and the odds of death in comparison with the reference group

\begin{tabular}{|c|c|c|c|c|}
\hline & \multicolumn{4}{|c|}{$\begin{array}{l}\% \text { of inpatient } \\
\text { death within each }\end{array}$} \\
\hline & group & n & OR & $\mathrm{Cl}$ for $\mathrm{OR}$ \\
\hline Total & 100 & 54 & & \\
\hline $\begin{array}{l}I S S<24 \\
I S S \geqslant 25\end{array}$ & $\begin{array}{r}3.8 \\
29.3\end{array}$ & $\begin{array}{r}3 \\
51\end{array}$ & $\begin{array}{r}1.0 \\
11.3\end{array}$ & $\begin{array}{l}\text { Reference } \\
3.4 \text { to } 37.6\end{array}$ \\
\hline $\begin{array}{l}\text { Age }<44 \\
\text { Age } 45-64 \\
\text { Age }>65\end{array}$ & $\begin{array}{l}17.0 \\
22.1 \\
28.8\end{array}$ & $\begin{array}{l}20 \\
17 \\
17\end{array}$ & $\begin{array}{l}1.0 \\
1.7 \\
2.1\end{array}$ & $\begin{array}{l}\text { Reference } \\
0.8 \text { to } 3.7 \\
1.0 \text { to } 4.6\end{array}$ \\
\hline
\end{tabular}

ISS, injury severity score. severity. It is important to note, however, that numbers in each group were small.

To explore the effect of the presence of flail on mortality in critical traumatic injuries, death rates of patients with flail were compared with those of patients in the database with no flail among the four severity and diagnoses groups. The percentage of mortality among the extrathoracic minor diagnoses (abbreviated injury score (AIS) severity $\leqslant 3$ ) is $12 \%$ among those with flail chest and $0.7 \%$ among those with no-flail chest. When bilateral flail and crush chest were excluded, mortality in the cases of flail and extrathoracic minor injury dropped further to $6 \%$. Unilateral flail was infrequently a reason for death, but additional injuries increased the mortality. The overall inpatient mortality for all flails with TBI $(\mathrm{n}=70)$ was $34 \%$. The combination of flail chest and TBI but no other major injury site $(n=52)$ had an inpatient mortality of $25 \%$, whereas the presence of an additional major injury (defined as AIS severity $\geqslant 4$ ) resulted in a markedly increased inpatient mortality of $61.1 \%$ $(\mathrm{n}=18)$. Table 3 lists these results.

The cause of death in 17 inpatients with flail chests with no other major extrathoracic injuries was as follows: bilateral flail $(n=7)$, crush chest $(n=2)$, aortic tear $(n=1)$, severe lung laceration (massive haemorrhage; $\mathrm{n}=1$ ), multiple fracture $((\mathrm{n}=1$; aged 78 years $)$, severe myocardial contusion $(n=1)$, and no specific single factor $(n=4)$. However, three of the latter patients reported having various limb fractures and one had a fracture of the skull base.

\section{DISCUSSION}

Road crashes account for most of the flail chest injuries. Accordingly, the phenomenon is seldom an isolated injury and severe, even critical, associated damage, mostly extrathoracic, is frequently present. In fact, the severity of the accompanying trauma is the main determinant of the eventual outcome in the presence of unilateral flail chest.

Most of these patients had multiple injuries and the flail chest was often not accorded treatment priority. Whenever the flail was indeed the main priority, it was handled according to well-established principles which evolved since Trinkle et al published their ground-breaking study in 1975, arguing that the respiratory insufficiency resulting from flail chest was due to lung contusion and was not brought about by paradoxical respiration. ${ }^{7}$ Consequently, they reasoned that management protocols should be directed to avoidance of fluid overload and intensive tracheobronchial toilet. Their results showed that by selectively deploying such methods, mortality could be considerably reduced. Today, aggressive control of pain is also emphasised.

Surgical fixation of the flail segment was not considered a treatment alternative in this series of patients. ${ }^{8}{ }^{9}$

Dissection of mortality figures in this series of flail chests is rather complicated as most deaths occurred in patients who had additional severe injuries. ${ }^{10}{ }^{11}$ Accordingly, we attempted to relate to the relevance of various features associated with the flail injury and their contribution to the patient's death. Overall mortality in our cohort was $20.6 \%$ (54 cases). Inpatient death rate was highest early on, $68.5 \%$ of the 54 deaths occurring within the first $24 \mathrm{~h}$. This may be explained by the grave severity of the damage, combined with the fact that Israel is a small country with trauma centres located throughout its length and breadth and that evacuation time to the hospital is relatively short. Consequently, many of those having non-salvable damage are still alive on arrival to the emergency room.

Increased age has been reported as influencing death rates in patients with flail chest. ${ }^{6}$ When taken by itself, mortality rose with advancing age, as shown in our breakdown to the three age groups mentioned earlier when presenting 
Table 3 Number and percentage of mortality in combination groups

\begin{tabular}{|c|c|c|c|c|c|c|}
\hline & \multicolumn{3}{|c|}{ Flail chest } & \multicolumn{3}{|c|}{ Other traumatic injuries } \\
\hline & $\begin{array}{l}\text { Group } \\
\text { size }\end{array}$ & $\begin{array}{l}\text { Number } \\
\text { dead }\end{array}$ & $\begin{array}{l}\text { Mortality } \\
\%\end{array}$ & $\begin{array}{l}\text { Group } \\
\text { size }\end{array}$ & $\begin{array}{l}\text { Number } \\
\text { dead }\end{array}$ & $\begin{array}{l}\text { Mortality } \\
\%\end{array}$ \\
\hline Total & 262 & 54 & 20.6 & 118211 & 2473 & 2.0 \\
\hline Other minor & r 159 & 19 & 11.9 & 104651 & 783 & 0.7 \\
\hline Other major & r 33 & 11 & 33.3 & 2158 & 400 & 18.5 \\
\hline $\mathrm{TBI}$ and & 52 & 13 & 25.0 & 11050 & 1123 & 10.2 \\
\hline $\begin{array}{l}\text { other minor } \\
\text { TBI and } \\
\text { other major }\end{array}$ & 18 & 11 & 61.1 & 352 & 167 & 47.4 \\
\hline
\end{tabular}

outcomes (tables 1 and 2). The severity of the injury is, however, the most important factor at all ages, whatever the multifactor combination.

Our results clearly show that unilateral flail, by itself, seldom leads to death. The overwhelming majority of deaths in patients who had sustained unilateral flail chest trauma were due to multiple, severe, extrathoracic injuries which resulted in mortality of $61.1 \%$.

As it was shown that unilateral flail is infrequently a reason for death, we tried to ascertain whether the presence of flail considerably increases the mortality in other critical traumatic injuries. We therefore compared all mortality due to flail with that of patients in the registry who had no flail (table 3). The percentage of mortality among the extrathoracic minor diagnoses was $12 \%$ among the flail chest cases and $0.7 \%$ among the no-flail chest cases. However, if bilateral flail and crush chest are excluded, mortality in the flail and extrathoracic minor injury drops to $6 \%$. Thus, in our series, this figure emerges as the death rate for patients with isolated unilateral flail injury. The percentage of mortality is higher for patients with flail (including bilateral flail) in each of the diagnosis groups. Other major diagnoses appear to be more severe in the flail groups, confirming once more that flail is usually associated with severe other injuries.

ISS categorisation confirms that those who died suffered increased additional damage compared with those who lived: their mean (standard deviation (SD)) ISS being 46.76 (17.32) compared with 36.76 (9.34) in the survivors. Clearly, bilateral flail chest denotes severe thoracic cage damage often accompanied by additional major injuries resulting in increased mortality.

TBI was a common accompanying injury and was associated with a mortality of $34.3 \%$. However, if TBI was the only additional serious injury the mortality dropped to $25 \%$. The total number of severe TBIs, no flail and no other major injury listed during the 6-year period of this study reached 11050 , with a mortality of only $10.2 \%$. Interestingly, the number of TBIs, no flail, but other major injury listed was 352 , with mortality rising to $47.4 \%$. Apparently, the severity of other injuries, as regards flail and TBI, determines the outcome. Nevertheless, TBI, without any other major extrathoracic organ damage in patients with flail injury, did raise mortality from $15.6 \%$ to $25 \%$ in this cohort.

\section{CONCLUSIONS}

Flail chest injury, most commonly caused by motor vehicle accidents, often denotes very serious general tissue damage. As drivers and pedestrians are frequently involved, preventive strategies should be targeted accordingly. Most of the deaths occur soon after arrival in the emergency room or in the first
24 h. Early mortality rates being so high, measures should be implemented to save some of these patients. Advanced age, considered by itself, was associated with increased mortality. However, when severity of injury was factored in, increased mortality in the elderly was less impressive. Supervening TBI considerably increases mortality in patients with flail chest. By implementing modern ventilation techniques and aggressive pain management, few patients with isolated, unilateral flail chest and lung contusion, and with no additional intrathoracic damage, should succumb to such injury. Death in patients with flail, who make it to the emergency department, is often associated with additional involvement of extrathoracic trauma. Although numbers are small, the high severity rating of the sustained trauma (and the related mortality) is likely to be due to the combination of flail chest and the additional damage caused by the accident.

\section{Authors' affiliations}

J B Borman, L Aharonson-Daniel, B Savitsky, K Peleg, Israel National Center for Trauma and Emergency Medicine Research, Gertner Institute for Epidemiology and Health Policy Research, Sheba Medical Center, Tel Hashomer, Israel

Competing interests: None declared.

The Israeli Trauma Group includes heads of trauma units participating in the National Trauma Registry: Drs Alficci R, Jeroukhimov J, Kluger $Y$, Klein Y, Kessel B, Michelson M, Rivkind A, Shaked G, Simon D, Soffer D, Stein $M$ and Waxman I

\section{REFERENCES}

1 Adegboye VO, Ladipo JK, Brimmo IA, et al. Blunt chest trauma. Afr J Med Med Sci 2002:31:315-20.

2 Leo $\mathrm{F}$, Venissac N, Lopez $\mathrm{S}$, et al. Anterior flail chest and sternal fracture: to fix or not to fix? [comment]. Asian Cardiovasc Thorac Ann 2003;11:188.

3 Liman ST, Kuzucu A, Tastepe Al, et al. Chest injury due to blunt trauma. Eur J Cardiothorac Surg 2003;23:374-8.

4 Balci AE, Eren S, Cakir O, et al. Open fixation in flail chest: review of 64 patients. Asian Cardiovasc thorac Ann 2004;12:11-15.

5 Athanassiadi K, Gerazounis M, Theakos N. Management of 150 flail chest injuries: analysis of risk factors affecting ourtcome. Eur J Cardiothorac Surg 2004;26:373-6.

6 Albaugh G, Kann B, Puc MM, et al. Age-adjusted outcomes in traumatic flail chest injuries in the elderly. Am Surg 2000;66:978-81.

7 Trinkle JK, Richardson JD, Franz JL, et al. Management of flail chest without mechanical ventilation. Ann Thorac Surg 1975;19:355-63.

8 Voggenreiter G, Neudeck F, Aufmkolk M, et al. Operative chest wall stabilization chest-outcomes of patients with or without pulmonary contusion. J Am Coll Surg 1998;187:130-8.

9 Tanaka H, Yukioka T, Yamaguti Y, et al. Surgical stabilization of internal pneumatic stabilization? A prospective randomized study of management of severe flail chest patients. J Trauma Injury Infect Crit Care 2002;52:727-32.

10 Yalcinkaya I, Sayir F, Kurnaz M, et al. Chest trauma: analysis of 126 cases [Turkish]. Ulusal Travma Dergisi (Turk J Trauma Emerg Surg 2000;6:288-91.

11 Velmahos GC, Vassiliu P, Chan LS, et al. Influence of flail chest on outcome among patients with severe thoracic cage trauma. Int Surg 2002;87:240-4. 